\title{
Streamlining Proses Bisnis Penyiapan Press Release Inflasi
}

\author{
Fitral Pratomo \\ Badan Pusat Statistik Provinsi Aceh \\ fitral@bps.go.id
}

\begin{abstract}
Abstrak
Badan Pusat Statistik (BPS) Provinsi Aceh rutin melakukan press release inflasi. Proses penyiapan press release tersebut membutuhkan waktu yang tidak sedikit. Di samping itu, data inflasi yang dimuat dalam press release ini dirujuk oleh berbagai pihak seperti peneliti, instansi, maupun media masa. Dengan demikian, kualitas data yang disajikan harus tetap terjaga. Kajian ini ditujukan untuk menemukan proses penyiapan press release yang lebih efektif dan efisien dengan tetap menjaga kualitas data inflasi yang disajikan. Metode yang digunakan adalah Business Process Improvement (BPI) dengan mengacu pada 12 tools streamlining hingga ditemukan proses bisnis usulan. Selanjutnya dilakukan simulasi antara proses bisnis awal dengan proses bisnis usulan yang ditemukan. Simulasi tersebut membuktikan bahwa proses bisnis usulan mampu mereduksi waktu penyiapan press release secara signifikan hingga $74 \%$. Aktifitas proses bisnispun berkurang jumlahnya dari 14 aktifitas menjadi 9 aktifitas. Di sisi lain, pemilihan salah satu tool streamlining yaitu automation diharapkan mampu menjaga kualitas data inflasi yang disajikan. Melalui kajian ini, peneliti juga menemukan bahwa metode BPI terbukti mampu merekomendasikan proses bisnis penyiapan press release yang lebih efektif dan efisien.
\end{abstract}

Kata kunci: automation; bizagi modeler; business process improvement; time analysis

\begin{abstract}
BPS-Statistics of Aceh Province routinely carries out inflation press releases. The process of preparing the press release requires a lot of time. Besides, the inflation data published in this press release was referred to by various parties such as researchers, agencies, and the mass media. Thus, the quality of the data presented must be maintained. This study is aimed at finding a more effective and efficient press release preparation process while maintaining the quality of the inflation data presented. The method used is the Business Process Improvement (BPI) regarding the 12 streamlining tools until the proposed business process is found. Furthermore, a simulation is carried out between the initial business processes and the proposed business processes that are found. This simulation proves that the proposed business process can significantly reduce press release preparation time by up to $74 \%$. The number of business process activities decreases from 14 activities to 9 activities. On the other hand, choosing one of the streamlining tools, namely automation, is expected to be able to maintain the quality of the inflation data presented. Through this study, researchers also found that the BPI method was proven to be able to recommend a more effective and efficient business process for press release preparation.
\end{abstract}

Keywords: automation; bizagi modeler; business process improvement; time analysis

\section{Pendahuluan}

BPS Provinsi Aceh rutin melakukan press release atau Berita Resmi Statistik (BRS) Indeks Harga Konsumen/Inflasi. Banyaknya data dan tabel yang disajikan, mengakibatkan proses penyiapan BRS Inflasi membutuhkan waktu yang tidak sedikit. Di samping itu, data inflasi yang dimuat dalam BRS ini dirujuk oleh berbagai pihak seperti peneliti, instansi, maupun media masa [1]-[4]. Peluang terjadinya human error dalam 
proses penyiapan BRS perlu diantisipasi, karena menyangkut kredibilitas [5]. Fakta-fakta tersebut menunjukkan perlunya proses penyiapan BRS Inflasi yang lebih baik.

Sepanjang pengetahuan penulis, penelitian tentang press release masih terbatas [6]. Namun, beberapa studi pada berbagai bidang lain telah dilakukan dengan menggunakan streamlining tools yang terdapat pada metode Business Process Improvement (BPI). Hasil berbagai penelitian tersebut memperlihatkan adanya proses bisnis yang lebih cepat sebagai outputnya [7]-[11]. Pada kajian ini, BPI akan diterapkan untuk menemukan proses penyiapan BRS Inflasi yang lebih efektif dan efisien, serta terjaganya kualitas data yang disajikan. Kajian ini akan didedikasikan bagi BPS Provinsi Aceh serta peneliti lain yang ingin melakukan perbaikan proses bisnis di bidang apapun.

\section{Tinjauan Pustaka}

\subsection{Penelitian Terkait}

Beberapa hasil penelitian yang mendukung langkah penulis untuk menggunakan streamlining tools yang terdapat pada metode Business Process Improvement (BPI) antara lain - Pada penelitian yang berjudul "Business Process Improvement Using Business Process Modelling Notation (BPMN) at Fika Crispy Mushroom", Y. D. P. Negara dan A. F. Doni merekomendasikan proses bisnis transaksi persediaan yang $60 \%$ lebih cepat serta proses bisnis transaksi pemesanan yang lebih cepat $70 \%$ [7].

- Pada penelitian yang berjudul "Perbaikan Proses Bisnis Logistik Sampah di Kota Cirebon Menggunakan Metode Business Process Improvement (BPI)", $\quad$ Sutandi merekomendasikan proses bisnis yang mampu meningkatkan kinerja truk pengangkut sampah dari TPS ke TPA sebesar $34,31 \%$ sehingga dapat mengurangi penumpukan sampah di TPS [9].

- Pada penelitian yang berjudul "Evaluasi dan Perbaikan Proses Bisnis Proyek Palapa Ring (PARING) Menggunakan Metode Business Process Improvement (BPI) (Studi Kasus: Badan Aksesibilitas Telekomunikasi dan Informasi)", Anggara Cahya Nugraha, Buce Trias Hanggara, dan Nanang Yudi Setiawan merekomendasikan proses bisnis Pembangunan Telekomunikasi PARING yang durasi penyelesaiannya lebih cepat hingga 1 hari 17 Jam 19 Menit 22 Detik [11].

\subsection{Landasan Teori}

BPI merupakan metodologi sistematis yang dikembangkan untuk membantu organisasi membuat kemajuan signifikan dalam menjalankan proses bisnisnya. Lima fase dalam BPI yaitu, organizing for improvement, understanding the process, streamlining, 
DOI : 10.29408/jit.v4i2.3370 Link : https://dx.doi.org/10.29408/jit.v4i2.3370

measurement and controls, continuous improvement [12]. Pada penelitian ini, BPI hanya dilakukan sampai fase streamlining saja. Fase streamlining akan mendeskripsikan dasar terpenting dari suatu perbaikan proses bisnis [12]. Streamlining akan menciptakan perubahan positif dalam efektivitas, efisiensi, dan kemampuan beradaptasi [12].

Ada 12 tool streamlining yang dapat diterapkan dalam urutan berikut: bureaucracy elimination, duplication elimination, value-added assessment, simplification, process cycle-time reduction, error proofing, upgrading, simple language, standardization, supplier partnerships, big picture improvement, automation and/or mechanization [12].

\section{Metode Penelitian}

Penelitian dilakukan dengan tiga tahap. Tahap memperoleh gambaran tentang proses bisnis yang berjalan. Tahap meningkatkan (improve) proses bisnis. Dan tahap simulasi proses bisnis.

3.1. Gambaran tentang proses bisnis yang berjalan

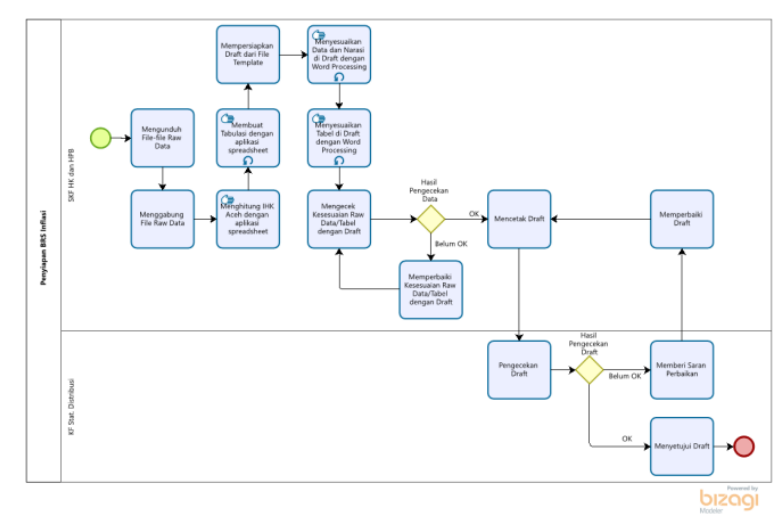

Gambar 1 Proses Bisnis Penyiapan BRS Inflasi

Di tahap ini, fase BPI organizing for improvement dan understanding the process akan dilalui. Wawancara dan observasi dilakukan untuk memperoleh informasi terkait proses bisnis yang berjalan. Kemudian pemodelan proses bisnis dilakukan dengan menggunakan aplikasi Bizagi Modeler. Bizagi Modeler merupakan tools untuk pemodelan/ manajemen proses bisnis yang memiliki dukungan simulasi [13], [14].

\subsection{Improve proses bisnis}

Tahap selanjutnya adalah menganalisis setiap aktivitas pada model proses bisnis berjalan. Dilanjutkan dengan improve proses bisnis menggunakan streamlining tools. Kemudian proses bisnis usulan tersebut dilakukan pemodelan.

\subsection{Simulasi proses bisnis}

Simulasi merupakan bentuk tiruan yang mirip dengan keadaan yang sesungguhnya. Pada tahap ini, proses bisnis yang berjalan dan 
proses bisnis usulan akan disimulasikan dengan menggunakan aplikasi Bizagi Modeler. Dengan demikian, kedua proses bisnis tersebut dapat dibandingkan.

\section{Hasil dan Pembahasan}

\subsection{Proses Bisnis yang Berjalan}

Wawancara dan observasi dilakukan pada Sub Fungsi Statistik Harga Konsumen dan Harga Perdagangan Besar (HK \& HPB).

Tabel 1 dan Gambar 1 memberikan gambaran tentang proses bisnis penyiapan BRS Inflasi yang berjalan. Ada 14 aktivitas dalam proses penyiapan BRS Inflasi.

Tabel 1. Deskripsi Proses Bisnis

\begin{tabular}{ll}
\hline Nama Proses & Penyiapan BRS Inflasi \\
\hline $\begin{array}{l}\text { Aktor yang } \\
\text { terlibat }\end{array}$ & $\begin{array}{l}\text { Sub Fungsi HK \& HPB, } \\
\text { KF Statistik Distribusi }\end{array}$ \\
\hline Deskripsi & $\begin{array}{l}\text { Penyiapan draf BRS Inflasi } \\
\text { Proses Bisnis } \\
\text { yang akan disampaikan saat } \\
\text { press release di setiap awal } \\
\text { bulan }\end{array}$ \\
\hline Input & Raw data dari BPS RI \\
\hline Output & Draf BRS Inflasi \\
\hline
\end{tabular}

\subsection{Improve Proses Bisnis}

Analisis dilakukan pada aktivitas-aktivitas yang terdapat pada proses bisnis penyiapan BRS Inflasi sebagaimana Tabel 2.

Kemudian, Tabel 3 menunjukkan bagaimana streamlining tools diterapkan untuk memperoleh proses bisnis usulan. Tool streamlining yang digunakan untuk melakukan improve proses bisnis adalah automation. Automation merupakan penerapan komputer pada aktivitas rutin [12].

Tabel 2. Analisis Proses Bisnis yang Berjalan

\begin{tabular}{|c|c|}
\hline Aktivitas & Isu \\
\hline $\begin{array}{l}\text { Menghitung } \\
\text { IHK }\end{array}$ & \multirow{2}{*}{$\begin{array}{l}\text { Aktivitas-aktivitas dilakukan } \\
\text { menggunakan aplikasi } \\
\text { spreadsheet. Butuh ketelitian } \\
\text { sehingga waktu pengerjaannya } \\
\text { relatif lama. }\end{array}$} \\
\hline $\begin{array}{l}\text { Membuat } \\
\text { Tabulasi }\end{array}$ & \\
\hline Menyesuaikan & \multirow{4}{*}{$\begin{array}{l}\text { Aktivitas-aktivitas dilakukan } \\
\text { berulang pada setiap poin } \\
\text { narasi dan pada setiap tabel. } \\
\text { Aktivitas-aktivitas dilakukan } \\
\text { menggunakan aplikasi word } \\
\text { processing. Ada peluang } \\
\text { human error. Aktivitas-aktivitas } \\
\text { juga berpeluang dilakukan } \\
\text { berulang kali jika aktivitas } \\
\text { Mengecek Data menemukan } \\
\text { kesalahan. }\end{array}$} \\
\hline $\begin{array}{l}\text { Data dan } \\
\text { Narasi di Draf }\end{array}$ & \\
\hline & \\
\hline $\begin{array}{l}\text { Menyesuaikan } \\
\text { Tabel di Draf }\end{array}$ & \\
\hline $\begin{array}{l}\text { Mengecek } \\
\text { Kesesuaian }\end{array}$ & $\begin{array}{l}\text { Aktivitas ini merupakan upaya } \\
\text { untuk menghilangkan peluang }\end{array}$ \\
\hline $\begin{array}{l}\text { Raw Data/ } \\
\text { Tabel dengan }\end{array}$ & $\begin{array}{l}\text { human error. Aktivitas ini } \\
\text { berpeluang dilakukan berulang }\end{array}$ \\
\hline Draf & $\begin{array}{l}\text { kali jika menemukan } \\
\text { kesalahan. }\end{array}$ \\
\hline
\end{tabular}

Tabel 3. Streamlining

\begin{tabular}{|c|c|c|}
\hline $\begin{array}{l}\text { Isu Proses Bisnis } \\
\text { Awal }\end{array}$ & $\begin{array}{l}\text { Streamlining } \\
\text { tool }\end{array}$ & $\begin{array}{l}\text { Rekomendasi } \\
\text { Proses Bisnis }\end{array}$ \\
\hline $\begin{array}{l}\text { Adanya aktivitas- } \\
\text { aktivitas yang } \\
\text { dilakukan manual } \\
\text { dengan } \\
\text { spreadsheet dan } \\
\text { word processing }\end{array}$ & $\begin{array}{l}\text { process cycle- } \\
\text { time reduction, } \\
\text { simplification, } \\
\text { automation }\end{array}$ & Penggunaan \\
\hline $\begin{array}{l}\text { Ada peluang } \\
\text { human error }\end{array}$ & $\begin{array}{l}\text { error proofing, } \\
\text { automation }\end{array}$ & $\begin{array}{l}\text { Otomasi BRS } \\
\text { Inflasi }\end{array}$ \\
\hline $\begin{array}{lr}\text { Adanya } & \text { aktivitas- } \\
\text { aktivitas r yang } \\
\text { berpeluang } \\
\text { dilakukan } \\
\text { kali jika } \\
\text { likulang } \\
\end{array}$ & automation & \\
\hline
\end{tabular}




\begin{tabular}{|c|c|c|c|}
\hline \multirow{4}{*}{$\begin{array}{ll}\text { Mengecek } & \text { Data } \\
\text { menemukan } & \\
\text { kesalahan } & \end{array}$} & $\begin{array}{l}\text { Instance } \\
\text { completed }\end{array}$ & 12 & 12 \\
\hline & Min. time & $3 \mathrm{~h} 2 \mathrm{~m}$ & $29 m$ \\
\hline & Max. time & $6 \mathrm{~h} 12 \mathrm{~m}$ & $2 \mathrm{~h} 13 \mathrm{~m}$ \\
\hline & Avg time & $4 \mathrm{~h} 2 \mathrm{~m}$ & $1 \mathrm{~h} 2 \mathrm{~m}$ \\
\hline
\end{tabular}

Penelitian ini merekomendasikan penggunaan aplikasi yang mampu meminimalisir kesalahan dan mempercepat proses [15]. Yaitu, aplikasi yang secara otomatis mampu membuat draf BRS Inflasi. Adapun pemodelan proses bisnis usulan dapat dilihat pada Gambar 2.

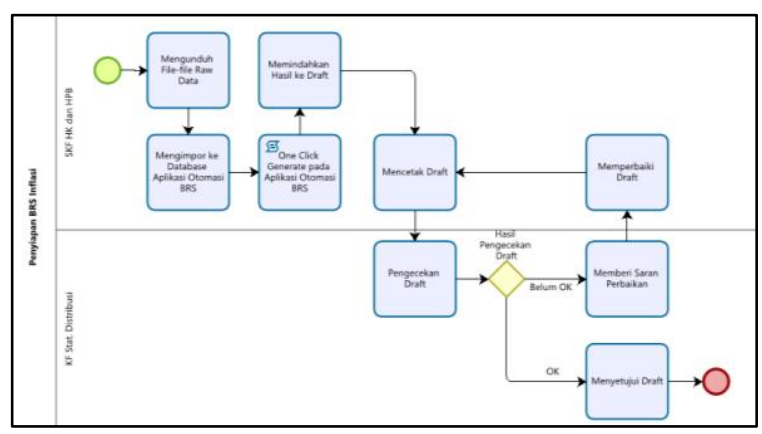

Gambar 2 Proses Bisnis Usulan

\subsection{Simulasi proses bisnis}

Simulasi Time Analysis dilakukan melalui fitur simulation view pada aplikasi Bizagi Modeler. Penyiapan BRS Inflasi selama satu tahun disimulasikan dalam 12 kali. Komparasi antara proses bisnis awal dengan proses bisnis usulan dapat dilihat pada Tabel 4. Simulasi menunjukkan penurunan waktu penyiapan BRS Inflasi dari 4 jam 2 menit menjadi 1 jam 2 menit atau sekitar $74 \%$.

Tabel 4. Time Analysis

\begin{tabular}{ccc}
\hline & $\begin{array}{c}\text { Proses Bisnis } \\
\text { Awal }\end{array}$ & $\begin{array}{c}\text { Proses Bisnis } \\
\text { Usulan }\end{array}$ \\
\hline Tasks & 14 & 9
\end{tabular}

\section{Kesimpulan}

1. Penelitian ini ditujukan untuk menemukan proses penyiapan BRS Inflasi yang lebih efektif dan efisien, dengan tetap menjaga kualitas data yang disajikan

2. Setelah diterapkan streamlining, 14 aktivitas pada proses bisnis penyiapan BRS Inflasi berkurang menjadi 9 aktivitas. Tool streamlining yang digunakan adalah automation.

3. Simulasi menunjukkan bahwa proses bisnis usulan mampu mereduksi waktu penyiapan BRS Inflasi secara signifikan hingga $74 \%$.

4. BPI mampu merekomendasikan proses bisnis penyiapan press release yang lebih efektif dan efisien.

\section{Daftar Pustaka}

[1] L. Wahyuni and Murtala, "Pengaruh Inflasi, Produk Domestik Regional Bruto dan Investasi Terhadap Pengangguran Terdidik di Provinsi Aceh," J. Ekon. Indones., vol. VIII, no. 2, pp. 26-31, 2020, doi: 10.29103/ekonomika.v9i2.3182.

[2] V. Fitria and S. Anwar, "Penerapan Triple Exponential Smoothing dalam Meramalkan Laju Inflasi Bulanan Provinsi Aceh Tahun 2019 - 2020," E-Jurnal Ekon. dan Bisnis Univ. Udayana, vol. 9, no. 1, pp. 23-38, Jan. 2020, doi: 10.24843/EEB.2020.v09.i01.p02. 
[3] Kantor Perwakilan Bank Indonesia Provinsi Aceh, "Laporan Perekonomian Provinsi Aceh Februari 2021," www.bi.go.id, 2021. https://www.bi.go.id/id/publikasi/laporan/lp p/Pages/Laporan-Perekonomian-ProvinsiAceh-Februari-2021.aspx (accessed Apr. 24, 2021).

[4] M. Husna, "Ikan Tongkol Sumbang Inflasi di Aceh," aceh.tribunnews.com, 2021. https://aceh.tribunnews.com/2021/02/01/i kan-tongkol-sumbang-inflasi-di-aceh (accessed Apr. 24, 2021).

[5] I. Khalid, "Kredibilitas Media Cetak dan Media Online," At-Tadabbur J. Penelit. Sos. Keagamaan, vol. 9, no. 1, pp. 84105, Mar. 2019.

[6] I. Gal and I. Ograjenšek, "Official Statistics and Statistics Education: Bridging the Gap," J. Off. Stat., vol. 33, no. 1, pp. 79-100, Mar. 2017, doi: 10.1515/jos-2017-0005.

[7] Y. D. P. Negara and A. F. Doni, "Business Process Improvement Using Business Process Modelling Notation (BPMN) at Fika Crispy Mushroom," in Proceedings of the 3rd International Conference on Social Sciences (ICSS 2020), 2020, vol. 473, no. Icss, pp. 777-782, doi: 10.2991/assehr.k.201014.168.

[8] R. Darma, H. Y. Sastra, Arhami, and F. Erwan, "Nutmeg Oil Production Process Analysis using Business Process Improvement-a Case Study," IOP Conf. Ser. Mater. Sci. Eng., vol. 1082, no. 1, p. 012005, Feb. 2021, doi: 10.1088/1757899X/1082/1/012005.

[9] S. Sutandi, "Perbaikan Proses Bisnis Logistik Sampah di Kota Cirebon Menggunakan Metode Business Process Improvement (BPI)," J. Logistik Indones., vol. 4, no. 1, pp. $64-73$, Oct. 2020, doi: 10.31334/logistik.v4i1.874.
[10] I. M. A. Pradnyana and I. M. E. Listartha, "Business process improvement design of complaints on technical information system problems using the business process improvement method," J. Phys. Conf. Ser., vol. 1810, no. 1, p. 012031 , Mar. 2021, doi: 10.1088/17426596/1810/1/012031.

[11] A. C. Nugraha, B. T. Hanggara, and N. Y. Setiawan, "Evaluasi dan Perbaikan Proses Bisnis Proyek Palapa Ring (PARING) Menggunakan Metode Business Process Improvement (BPI) (Studi Kasus: Badan Aksesibilitas Telekomunikasi dan Informasi)," J. Pengemb. Teknol. Inf. dan IImu Komput., vol. 4, no. 3, pp. 717-722, 2020.

[12] H. J. Harrington, Business Process Improvement The Breakthrough Strategy for Total Quality, Productivity, \& Competitiveness. New York: McGraw-Hill, 1991.

[13] K. Rosenthal, B. Ternes, and S. Strecker, "Business Process Simulation on Procedural Graphical Process Models," Bus. Inf. Syst. Eng., no. 2014, Apr. 2021, doi: 10.1007/s12599-021-00690-3.

[14] Daniel Tunggono Saputro, "Pembuatan Proses Bisnis Persiapan Material untuk Produksi dengan Business Process Modelling Notation (BPMN) di Pabrik Generator Sets (GENSET) PT ABC," J. Indones. Sos. Teknol., vol. 2, no. 1, pp. 23-38, 2021.

[15] A. Sudianto, H. Ahmadi, and A. Alimuddin, "Rancang Bangun Sistem Informasi Penjualan Sparepart Motor Pada Bengkel Vinensi Motor Berbasis Web Sebagai Guna Meningkatkan Penjualan dan Promosi Produk," Infotek J. Inform. dan Teknol., vol. 3, no. 2, pp. 115-122, Aug. 2020, doi: 10.29408/jit.v3i2.2289. 